\title{
Where Is the Global Environmental Bailout?
}

\author{
J. T. Trevors • M. H. Saier Jr.
}

Received: 20 October 2008 / Accepted: 21 October 2008 / Published online: 15 November 2008

(C) Springer Science + Business Media B.V. 2008

Keywords Environment · Crisis · World Finance ·

Bailout $\cdot$ Rescue plan

The autumn of 2008 has seen trillions of dollars disappearing from stock markets and investment funds. This has resulted from greed, ignorance, lack of foresight, and inadequate educations, particularly of our governmental officials. This is what comes of having poorly qualified people with big egos in office. As we prepare this article, an international conglomerate of governments is forming, trying to formulate a massive bank bailout plan with the hope that the fragile global economic system will recover. The 700 billion dollars already put up by the US government to bail out its banks - at middle class tax payers' expense for the next 100 years if American civilization lasts that long-has not been deemed

\footnotetext{
J. T. Trevors

Department of Environmental Biology,

University of Guelph,

Guelph, Ontario, Canada N1G 2W1

e-mail: jtrevors@uoguelph.ca

M. H. Saier Jr. $(\square)$

Division of Biological Sciences,

University of California, San Diego,

La Jolla, CA 92093-0116, USA

e-mail: msaier@ucsd.edu
}

successful. Some people believe that more credit must be made available to fuel consumption of renewable and nonrenewable resources in order to stimulate economic growth. Yet, the human population is now marching towards seven billion people, and we are already living painfully unsustainably. The planet is infected with too many humans. In fact, we are so far from sustainability that anyone with a brain is forced to predict global disaster resulting from global stupidity. This disaster is upon us now; the signs of further collapse are already here.

Our current system of free enterprise, which governments are now struggling to rescue, was designed for purposes of economic exploitation in a technological era. Our current rescue plans, designed by the people who got us into this mess, provide opportunity for even more pilfering. Some argue that these rescue plans will improve the standard of living for very few. It will benefit select people - those who do not need being rescued. It will once again allow the consolidation of wealth while leaving the vast majority of the human population poorer than ever and the planet more polluted. This may or may not be true, but one thing for sure: It will not help humanity and our common shared biosphere in the long run.

One would think that a well-designed and operated economic system, like a well-oiled machine, would go on without tinkering for a long time - as long as sufficient resources are available. We are now coming to realize, just as the world came to realize in 1929 , 
that this is not so. To be truly successful, any economic system must provide long-term benefits to humanity without depleting the resources and polluting the planet that we all depend on. This must be a primary objective. Of course, suggesting the achievement of this objective may be wishful thinking as greed is a powerful force. Unfortunately, feelings of charity and goodwill toward future residents of the earth as well as the current poorer members of society seem too often to be forgotten or neglected.

We all know that we need funds to implement a global environmental rescue plan, but no such plan seems to be on the horizon. It would take an annual 30-40 billion dollars, a trifling really, to provide universal birth control for the entire human population. This would be by far our best investment, but the USA, for one, or its current governmental officials, does not seem willing to even provide a tiny fraction of this meager sum. It would rather devote trillions for war and destruction, trillions for "home security", and trillions for an untested rescue plan that allows billions to be pocketed by its planners.

What if everyone recognized that the global crisis is not economic but environmental? Our environmental crisis, due to human overpopulation, encompasses global pollution and climate change, increased incidences and intensities of hurricanes, rising oceans with flooding, pollution of every kind, ozone depletion, food and fuel shortages, and pandemics. What if any one of these events were accompanied by collapse of public health infrastructure? What if several of these were to happen at the same timethe perfect storm!

In fact, all of these events threaten us today. Where is the international environmental rescue plan? Even if an environmental global rescue plan was implemented, how long would it take to see positive results, and would the results be uniform around the Planet? Answers to these questions are not available. Where are the trillions of dollars needed for the rescue of our faltering blue planet? Where are the funds that could stabilize and then reduce our human population? Where is the effort to conserve resources and biodiversity while providing the basic needs for our mushrooming population? And what if the laws of thermodynamics that govern all mass and energy transformations in the universe simply ignore our governments' plans to rescue this planet when it is too late? All that we devise as a means to rescue our planet from ourselves may be for naught if it is implemented too late. The next collapse of infrastructure may be the collapse of our biosphere. This pessimistic view may simply be reality. A precautionary approach seems advisable.

Our economic crisis is of little importance compared to the environmental crisis we are carelessly imposing on our global support system. It is likely to result in billions of human hardships, including starvation and premature death for millions and eventually billions. It has already caused the extinction of hundreds of thousands of species with an estimated 30,000 going extinct every year. But our current government officials are not concerned. One thing at a time, they say, and the economy is most important. After all, that is what is on everyone's minds.

However, the real crisis, environmental collapse, can be avoided if and only if the human population is reduced, and international studies have shown that this is a feasible goal requiring only that wealthy countries invest about 30-40 billion dollars per year to make birth control available to the world population. This is sufficient to reverse the current growth trend. It may be the only factor that will allow reduction of fossil fuel consumption to slow global warming. It will yield dividends of unheard of proportions.

The human population needs to recognize what their priorities must be. We need to replace local, national, and international conflicts with cooperation. We must start working for the betterment of humanity and the biosphere rather than for profit. Greed and dishonesty need to be replaced with humanitarian actions. Humanitarian organizations, the wealthy nations of the world, and everyone everywhere need to contribute to a well thought out, comprehensive, environmental rescue plan. We all need to contribute until it hurts, because the alternative is loss of our biosphere and species extinction with Homo sapiens being one of the casualties. Before humans disappear from the face of the Earth, human civilization will go by the wayside, resulting in incessant warfare, suffering, and destruction. We desperately need proper education, especially in the areas of human fertility, birth control, and global pollution. We need governmental leaders who are well educated, have 
foresight, and are willing to sacrifice personal gain for the betterment of humankind. We need a new era of reason and enlightenment.

There are no guarantees that the people of our nations will see the light, recognizing the real issues so that we can begin solving our most important problems. The real rescue plan for the planet is environmental not economic. Any rescue plan that does not aim to reduce the human population, the wasteful use of our resources and global pollution is doomed to failure. The economic rescue plan, while putting us all deeply into debt, squanders away our hopes for a quality future. It pales in comparison to the real world problem of rescuing our planet from ourselves. That is where our billions and trillions should be going. 